\title{
Environmental and Animal Defense
}

\section{Núria Almiron and Catia Faria}

\begin{abstract}
The controversy between the ultimate aims of environmental defense, on one hand, and animal defense, on the other, is a much unexplored topic. This special issue aims to fill this gap by gathering original thinking and outstanding research connected to the topics. We hope the unique discussion provided in this special issue is of help to philosophers, animal and environmental ethicists, critical animal studies scholars, and environmental sociologists, as well as to researchers in the fields of advocacy, communication, ecology, psychology, and anthrozoology.
\end{abstract}

Keywords: environmental defense, animal defense, animal ethics

It is a common mistake to think of modern animal defense as an appendix or a follow- up to environmental defense. Environmental scholars are probably the ones to blame for the original confusion between environmental ethics (the ethics of our treatment of natural entities) and animal ethics (the ethics of our treatment of other animals). Influential environmentalist thinkers such as J. B. Callicott (1980), for example, addressed concern for nonhuman animals from an environmental perspective, and other environmental authors followed suit by including animal rights in their list of environmental concerns (Corbett, 2006). The relationship this suggests between the two ethics, however, is misleading, for modern concern for nonhuman animals emerged as a public claim separate from the environmental movement. In academia, for example, it arose from moral philosophers engaged with social justice issues more than concern for the environment (Regan, 1983; Singer, 1975).

Moreover, environmental defense and animal defense are rooted in two radically different approaches. On the one hand, the land ethics approach that informs most environmental views allocates intrinsic value to so-called "biotic communities" - toward which we allegedly have moral obligations that justify, for instance, the practice of culling individuals of certain species to preserve the balance of ecosystems. On the other hand, the animal ethics stance stresses the fact that nonhuman animals are sentient individuals and are therefore due moral consideration. Animal ethics therefore views the perspective of environmentalist ethics on nonhuman animals as a form of speciesist discrimination.

A critical question arises from these profound differences: Is it possible for both defenses to act jointly? Are they inherently incompatible or is there room for them to join forces?

To discuss this question, the UPF Centre for Animal Ethics (UPF-CAE) and the THINKClima research project (both at the Universitat Pompeu Fabra) co-organized an international panel in Barcelona in September 2017 with the title, "Are the defense of animals and environmentalism compatible?" The discussion was distributed among panelists arguing for an affirmative answer to the question (that the two defenses are compatible) and those arguing for a negative answer (that they are incompatible). This special issue arises from the discussion begun at this panel and expands it with the aim of increasing the knowledge of the complex relations between 
environmental defense and animal defense. It includes some of the key points presented by Catia Faria, Eze Paez, and Lisa Kemmerer in the papers they presented at the event, as well as new complementary contributions from the fields of advocacy, communication, political economy, and psychology.

In "It's Splitsville: Why Animal Ethics and Environmental Ethics Are Incompatible," Catia Faria and Eze Paez argue that as a set of ethical views, the two positions are irreconcilable due to having different criteria of moral considerability as well as incompatible normative implications. Thus, they claim, we can support one of the two positions, but not both simultaneously. The authors argue that environmentalist positions lead to a hopeless dilemma: they are either inconsistent or have unacceptable consequences for the human case. In addition, they fail to acknowledge the importance of wild animal suffering. Faria and Paez therefore conclude that we ought to reject environmentalism and to endorse any view in animal ethics that takes the interests of sentient nonhuman animals seriously.

In "The Interconnected Nature of Animal Ethics and Environmental Ethics," Lisa Kemmerer argues against Faria and Paez's conclusion. According to Kemmerer, scholars and activists who focus on core philosophical differences fail to understand the interconnected nature of the universe as described by ecofeminists, Asian and indigenous philosophies, as well as science itself. Issues such as climate change and human overpopulation, she points out, are excellent examples of shared activist platforms in which environmentalists and animal rights activists ought to cooperate. While it is possible to identify core philosophical differences between the two parties, it is far more important to identify interconnected, shared concerns and to unite forces to help bring about change.

In "Toward a New Framework for Understanding Human-Wild Animal Relations," Daniela R. Waldhorn argues that psychology has traditionally framed the analysis of human-wild animal relations within environmental psychology, conceptualizing wild animals as merely one further component of nature. Though this approach is suitable for environmental and conservation purposes, the author argues that it fails to track our attitudes toward animals as individuals with a well-being of their own. By using Kellert's framework about factors affecting attitudes toward wildlife, she reviews and integrates existing findings in social psychology.

In "Greening Animal Defense? Examining Whether Appealing to Climate Change and the Environment Is an Effective Advocacy Strategy to Reduce Oppressions of Nonhumans," Núria Almiron addresses the dilemma of what arguments are best to advocate for nonhuman animals. This article attempts to contribute to this discussion by examining some of the reasons that best support or refute the use of an environmental frame for the defense of nonhuman animals from a non-speciesist and abolitionist perspective. The conclusion is that there are strong arguments for all stances, though, at least for long-term behavioral change, the use of green arguments seems to have more drawbacks.

In "Selling Eden: Environmentalism, Local Meat, and the Post-Commodity Fetish," Vasile Stănescu addresses the idealized view of farming as a return to an earlier time of supposed simplicity and "naturalness." As such, what local or so-called "humane" meat represents is not a viable environmentalist strategy but rather an imagined return to a supposedly "Edenic" time that never existed. According to Stănescu, the locavore movement's nostalgia for an "earlier" time appeals to a false representation of nature, which, precisely because it is artificial, requires constant and ongoing human intervention, even as its practitioners and advocates justify this intervention based on its sup- posed "naturalness."

Finally, in "Using Images of Farmed Animals in Environmental Advocacy. An Antispeciesist, Strategic Visual Communication Proposal," Laura Fernandez reviews the literature on strategic visual communication in animal liberation and environmental advocacy with a special focus on 
the animal agriculture industry. In particular, the article discusses two main issues: the historical invisibility of the role of animal agriculture in climate change and whether it is useful to include explicit violent images (producing moral shock) of farmed animals in environmental advocacy campaigns to fight against climate change and environmental devastation.

The controversy between the ultimate aims of environmental defense, on one hand, and animal defense, on the other, is a much unexplored topic. This special issue aims to fill this gap by gathering original thinking and outstanding research connected to the topics. We hope the unique discussion provided in this special issue is of help to philosophers, animal and environmental ethicists, critical animal studies scholars and environmental sociologists, as well as to researchers in the fields of advocacy, communication, ecology, psychology and anthrozoology.

\section{Funding}

The authors disclosed receipt of the following financial support for the research, authorship, and/or publication of this article: This research is supported by the Spanish State Research Agency (Agencia Estatal de Investigación, AEI) and the European Regional Development Fund (ERDF) by means of Grant CSO2016-78421-R.

\section{REFERENCES}

Callicott, J. B. (1980). Animal liberation: A triangular affair. Environmental Ethics, 2, 311-338. Corbett, J. (2006). Communicating nature: How we create and understand environmental messages. Washington, DC: Island Press.

Regan, T. (1983). The case of animal rights. Berkeley: University of California Press. Singer, P. (1975). Animal liberation. New York, NY: HarperCollins. 